\title{
Pengaruh Suhu Bahan Campuran Terhadap Sifat dan Mutu Beton Dalam Pelaksanaan Drainase Jalan pada Daerah Terpencil di Provinsi Kalimantan Selatan
}

\author{
The Effect of Mixed Material Temperature on Concrete Properties and \\ Quality in the Implementation of Remote Area Drainage in South \\ Kalimantan Province
}

\author{
Hudan Rahmani ${ }^{1, a)}$ \& Akhmad Gazali ${ }^{1, b)}$ \\ 1)Program Studi Teknik Sipil, Universitas Islam Kalimantan Muhammad Arsyad Al Banjari, \\ Banjarmasin
}

Koresponden : ${ }^{a)}$ uwa.hudan58@gmail.com \& ${ }^{b}$ akhmadgazali51@gmail.com.

\begin{abstract}
ABSTRAK
Pelaksanaan pekerjaan beton memerlukan pengawasan dan penanganan khusus dalam pengujian bahan-bahan yang dipilih sebagai bahan campuran beton, agar terbentuk beton dengan kekuatan maksimum dan ekonomis. Untuk menggunakan beton sebagai bahan bangunan ada persyaratan yang harus dipenuhi, termasuk sifat fisika agregat. Dalam kenyataan di lapangan akibat kurangnya pengawasan pengerjaan drainase jalan pada daerah terpencil di propinsi Kalimantan Selatan, sering dijumpai material campuran beton tidak terlindung dari panas matahari sehingga temperatur material tersebut naik dan temperature hasil adukannya juga ikut naik. Penelitian ini bertujuan untuk mengetahui pengaruh penggunaan material campuran beton yang mengalami pemanasan sinar matahari secara langsung dibandingkan dengan material yang terlindung dari panas matahari. Metode eksperimen dilakukan terhadap 2 variasi sampel dengan mutu beton rencana yang sama K-225, berjumlah 20 buah sampel untuk tiap variasinya. Dari hasil pemeriksaan kuat tekan rata-rata dan kuat tekan karakteristik diketahui bahwa agregat yang bertemperatur tinggi akibat panas matahari mempengaruhi faktor air-semen yang mengakibatkan pengikatan semen tidak optimal.
\end{abstract}

Kata Kunci : manajemen aset infrastruktur, pengadaan infrastruktur, campuran beton, pengaruh suhu, kuat tekan.

\section{PENDAHULUAN}

Dewasa ini perkembangan di bidang struktur dan arsitektur menyebabkan beton bukan hanya sebagai solusi untuk memenuhi akan tersedianya sarana dan prasarana penunjang pembangunan, tetapi keberadaan beton sebagai salah satu bahan konstruksi yang digunakan identik sebagai bentuk kehidupan sosial yang modern. Pelaksanaan pekerjaan yang mempergunakan beton memerlukan pengawasan dan penanganan yang khusus dalam pengujian bahan-bahan yang dipilih sebagai bahan campuran beton. Pada akhirnya diharapkan terbentuk beton dengan kekuatan maksimum dan komposisi campuran yang lebih ekonomis.

Sesuai Prinsip Manajemen Aset Infrastruktur (MAI), infrastruktur harus dikelola dengan baik agar selalu bisa berfungsi dengan baik, secara ekonomis, efisien dan efektif. Salah satu tahap penting dalam MAI adalah tahap Pengadaan Infrastruktur (Suprayitno \& Soemitro 2018). Salah satu masalah pada tahap Pengadaan Infrastruktur adalah masalah sifat dan mutu 
beton yang bisa berubah-ubah karena kondisi lapangan. Maka masalah khas ini perlu dikenali dengan baik.

Untuk menggunakan beton sebagai bahan bangunan ada persyaratan yang harus dipenuhi. Salah satunya adalah sifat agregat. Sifat-sifat agregat yang penting dalam pembuatan beton adalah bentuk, gradasi, kekuatan, modulus elastisitas serta interaksi fisika dan kimianya dengan pasta semen yang akan mempengaruhi rekatan antara agregat dan mortar. (Tanjung, 1995).

Dalam kenyataan di lapangan pada waktu akan dilakukan pengecoran beton, material yang digunakan jarang diperhatikan penempatannya. Contohnya seperti pengerjaan saluran drainase jalan pada daerah terpencil di propinsi Kalimantan Selatan. Akibat dari kurangnya pengawasan, sering ditemui material campuran beton tidak terlindung dari panas matahari sehingga temperatur material tersebut akan naik dan hasil adukan juga akan tinggi temperaturnya, secara alami kita akan melihat betapa besarnya pengaruh agregat yang panas bila tersentuh air, agregat tersebut akan cepat meresap air yang melekat di sisinya.

Menurut Amirudin (2011) pengecoran-beton-saat-cuaca-panas-akibat-sinar matahari/ menyatakan bahwa suhu panas dari panas matahari dan tiupan angin yang kencang dan kering mempengaruhi beton sehingga lekas kaku dan sangat menyulitkan dalam pengerjaan pengecoran seperti penempatan, perataan dan pemadatan hal ini akan berujung dengan mutu beton yang turun dapat sampai ke angka 15\% lebih rendah selain itu bentuk visual yang bisa saja keropos dan tidak halus permukaanya, sehingga menggoda tukang untuk menambahkan air pada adukan yang mana ini tabu bagi mutu beton.

Berdasarkan kondisi di atas maka penulis bermaksud meneliti seberapa jauh pengaruh penggunaan material campuran beton yang mengalami pemanasan sinar matahari secara langsung dibandingkan dengan bahan campuran beton yang terlindung dari panas matahari.

Penelitian ini hanya terbatas pada pemeriksaan bahan agregat, semen, campuran beton (mix design) dan pengujian kuat tekan beton pada mutu beton K-225, dengan bahan campuran yang sama yaitu kerikil dari Kandangan, pasir dari Rantau, Semen Portland merek Tiga Roda dan air dari PDAM.

\section{METODA PENELITIAN}

\section{Rencana Rangkaian dan Rencana Penelitian}

Penelitian ini dilaksanakan dengan metode eksperimen, yaitu melaksanakan eksperimen/ percobaan di laboratorium. Perlakuan di laboratorium dikondisikan sama dengan keadaan di lapangan atau diusahakan mendekati kondisi di lapangan.

Sampel yang digunakan dalam bentuk kubus dengan ukuran sisi-sisinya $150 \times 150 \times$ $150 \mathrm{~mm}$. Dalam penelitian ini penulis membuat 2 (dua) variasi sampel dengan mutu beton rencana yang sama K-225 dan berjumlah 20 buah sampel untuk tiap variasinya. Adapun bahan-bahan yang digunakan dalam penelitian ini adalah sebagai berikut : 
Tabel 1. Daftar Temperatur Bahan-bahan dan Adukan Yang Dipergunakan Dalam Pelaksanaan Penelitian

\begin{tabular}{cccccc}
\hline \multirow{2}{*}{$\begin{array}{c}\text { Variasi } \\
\text { perlakuan) }\end{array}$} & Kerikil & Pasir & $\begin{array}{c}\text { Semen } \\
\text { Portland }\end{array}$ & Air & Adukan \\
\cline { 2 - 6 } & $\mathbf{( 2 )}$ & $\mathbf{( 3 )}$ & $\mathbf{( 4 )}$ & $\mathbf{( 5 )}$ & $\mathbf{( 6 )}$ \\
\hline $\mathbf{( 1 )}$ & Kandangan & Rantau & Tiga Roda & PDAM & Campuran $2,3,4$ dan 5 \\
\hline I (Terlindung) & $\left(\right.$ Temp. $\left.30^{\circ} \mathrm{C}\right)$ & $\left(\right.$ Temp. $\left.31^{\circ} \mathrm{C}\right)$ & $\left(\right.$ Temp. $\left.30^{\circ} \mathrm{C}\right)$ & $\left(\right.$ Temp. $\left.29^{\circ} \mathrm{C}\right)$ & Temp. $30^{\circ} \mathrm{C}$ \\
\hline II (Dipanaskan) & Kandangan & Rantau & Tiga Roda & PDAM & Campuran $2,3,4$ dan 5 \\
\hline & $\left(\right.$ Temp. $\left.40^{\circ} \mathrm{C}\right)$ & $\left(\right.$ Temp. $\left.41^{\circ} \mathrm{C}\right)$ & $\left(\right.$ Temp. $\left.33^{\circ} \mathrm{C}\right)$ & $\left(\right.$ Temp. $\left.35^{\circ} \mathrm{C}\right)$ & Temp. $40^{\circ} \mathrm{C}$ \\
\hline
\end{tabular}

Semua bahan agregat dalam penelitian ini adalah agregat alami. Kerikil Kandangan dan pasir Rantau adalah bahan agregat. Dipilihnya agregat ini karena secara teknis dan kualitasnya baik, selain itu agregat ini sering dipergunakan pada proyek-proyek pembangunan yang dilaksanakan di lingkungan Kalimantan Selatan.

Semen Portland dipilih semen Tiga Roda type I, karena mudah didapatkan di pasaran dan realisasi hasil percobaan ini lebih mendekati kenyataan di lapangan yang dipergunakan untuk kegiatan pembangunan.

Air yang dipergunakan adalah air PDAM agar persyaratan pemilihan air sebagai bahan campuran beton dan sebagai media perawatan beton telah terpenuhi.

\section{PENGUMPULAN DATA}

\section{Pemeriksaan Bahan}

Pemeriksaan bahan dilakukan bertujuan untuk mengetahui kelayakan bahan sebagai material beton yang memenuhi syarat untuk dipergunakan dalam pembuatan campuran beton dan untuk mengumpulkan data untuk perencanaan campuran beton (mix design).

Berdasarkan acuan buku Petunjuk Praktikum Beton yang diterbitkan oleh Laboratorium Struktur dan Bahan Fakultas Teknik Universitas Lambung Mangkurat (FT ULM, 1995). Pemeriksaan bahan dilakukan dengan rancangan pekerjaan di laboratorium yang meliputi :

1. Pemeriksaan Berat jenis semen Portland

2. Pemeriksaan konsistensi normal semen Portland

3. Penentuan waktu pengikatan semen Portland

4. Pemeriksaan berat isi agregat halus dan agregat kasar

5. Analisa saringan agregat halus dan agregat kasar

6. Pemeriksaan kadar lumpur agregat halus dan agregat kasar lewat saringan No.16 dan No.200

7. Pemeriksaan Kadar organik dalam agregat halus

8. Pemeriksaan kadar air agregat kasar dan halus

9. Analisa specific-gravity dan absorpsi agregat halus dan kasar

10. Pemeriksaan abrasi agregat kasar

\section{Perencanaan Campuran (mix design)}

Perhitungan perencanaan campuran beton (mix design) ini dilakukan dengan metode literatur yaitu mengacu pada SK SNI 03-2834-2000 tentang Tata Cara Pembuatan Rencana Campuran Beton Normal. Perencanaan campuran beton bertujuan mendapatkan komposisi campuran antara semen Portland, pasir, kerikil dan air untuk membantu proses kimia (SNI 032834-2000). 


\section{Pembuatan Benda Uji}

Benda uji pada penelitian ini dibuat dalam 1 (satu) macam perencanaan campuran terhadap rencana tegangan rata-rata. Jumlah semen dan air sama, namun perlakuan terhadap semua bahan berbeda. Variasi pertama semua bahan diberi perlindungan (atap) dan variasi kedua dipanaskan pada terik matahari, diukur temperatur bahan pada setiap saat memasukkan ke alat pengaduk begitu juga temperatur hasil adukan.Jumlah sampel untuk setiap variasi akan sama yaitu 20 buah sampel. Pada saat pembuatan sampel (benda uji), slump pada setiap variasi sampel akan diukur.

\section{Pengetesan Benda uji}

Kedua variasi Benda Uji akan dilakukan pengetesan atau pengujian terhadap kekuatan tekan beton setelah sampel berumur 28 hari sesudah pengecoran.

\section{ANALISIS PENELITIAN}

Sebelum membuat mix design dan memulai pembuatan campuran beton, maka diperlukan pemeriksaan bahan-bahan yang dipergunakan dalam campuran beton tersebut. Selain itu dari pemeriksaan bahan akan diperoleh data yang diperlukan dalam perencanaan campuran beton (mix design). Bahan-bahan yang akan dipergunakan dalam pelaksanaan penelitian ini terdiri dari pasir dan kerikil Kandangan, air PDAM dan semen Portland Tiga Roda. Berdasarkan Buku "Petunjuk Praktikum Beton" yang dikeluarkan oleh Laboratorium Struktur dan Bahan Fakultas Teknik Universitas Lambung Mangkurat diperoleh rangkuman pemeriksaan bahan-bahan seperti tersebut diatas pada tabel dibawah ini.

Tabel 2. Hasil Pemeriksaan Semen Portland (Tiga Roda)

\begin{tabular}{lc}
\hline \multicolumn{1}{c}{ Jenis Pemeriksaan } & $\begin{array}{c}\text { Hasil Pemeriksaan } \\
\text { Semen Tiga Roda }\end{array}$ \\
\hline 1. Berat Jenis $\left(\mathrm{gr} / \mathrm{cm}^{2}\right)$ & 3,15 \\
2. Konsistensi Normal (\%) & 22 \\
Jumlah Air & 110 \\
Penurunan & 10 \\
3. Waktu Pengikatan & 44.25 \\
- Waktu Pengikatan Awal & 1,750 \\
- Waktu Pengikatan Akhir & \\
\hline
\end{tabular}

Tabel 3. Hasil Pemeriksaan Bahan Agregat Halus

\begin{tabular}{lc}
\hline \multicolumn{1}{c}{ Jenis Pemeriksaan } & $\begin{array}{c}\text { Hasil Pemeriksaan } \\
\text { Pasir Rantau }\end{array}$ \\
\hline 1.Berat Volume $\left(\mathrm{gr} / \mathrm{cm}^{2}\right)$ & 1.400 \\
\hline 2.Kadar Air (\%) & 4,142 \\
\hline 3. Kadar Lumpur (\%) & 2,511 \\
\hline 4.Analisa Saringan & Zone I \\
\hline 5.Specific Gravity \& Absorpsi & \\
- Apparent Specific Gravity & 2,535 \\
- Bulk Specific Gravity (dry) & 2,300 \\
- Bulk Specific Gravity (SSD) & 2,392 \\
- Absorpsi & 4,040 \\
\hline 6.Kadar Organik & Standar Warna No.3 \\
\hline
\end{tabular}


Tabel 4. Hasil Pemeriksaan Bahan Agregat Kasar

\begin{tabular}{llc}
\hline \multicolumn{1}{c}{ Jenis Pemeriksaan } & $\begin{array}{c}\text { Hasil Pemeriksaan } \\
\text { Kerikil Kandangan }\end{array}$ \\
\hline 1. & Berat Volume $\left(\mathrm{gr} / \mathrm{cm}^{2}\right)$ & 1,802 \\
\hline 2. & Kadar Air (\%) & 1,975 \\
\hline 3. & Kadar Lumpur (\%) & 2,40 \\
\hline 4. & Analisa Saringan & Zona I \\
\hline 5. & Specific Gravity \& Absorpsi & \\
& • Apparent Specific Gravity & 1,372 \\
& • Bulk Specific Gravity (dry) & 1,375 \\
& • Bulk Specific Gravity (SSD) & 2,595 \\
& • Absorpsi (\%) & 8,910 \\
\hline 6. & Abrasi (\%) & 23.10 \\
\hline
\end{tabular}




\section{Rangkuman Perencanaan Campuran (mix design)}

Dengan mengikuti SNI 03-2834-2000 tentang Tata Cara Pembuatan Rencana Campuran Beton Normal, diperoleh rangkuman Mix Design sebagai berikut :

Tabel 5a. Rangkuman Perencanaan Campuran

\begin{tabular}{|c|c|c|}
\hline No.Uraian & Perhitungan & Nilai \\
\hline (1) & (2) & (3) \\
\hline $\begin{array}{l}\text { 1. Kuat tekan yang } \\
\text { diisyaratkan }\end{array}$ & Ditetapkan & $\begin{array}{l}22,5 \mathrm{~N} / \mathrm{mm}^{2} \text { pada } 28 \text { hari. Kemungkinan } \\
\text { gagal } 5 \text { persen }\end{array}$ \\
\hline 2. Deviasi standar & & $\begin{array}{l}5 \mathrm{~N} / \mathrm{mm}^{2} \text { atau tanpa data } \ldots . . \\
5 \times 1,08=5,4 \mathrm{~N} / \mathrm{mm}^{2}\end{array}$ \\
\hline 3. Nilai Tambah (margin) & & $(\mathrm{k}=1,64) 1.64 \times 5,4=8,86 \mathrm{~N} / \mathrm{mm}^{2}$ \\
\hline 4. Rencana tegangan rata-rata & $1+3$ & $22,5+8,86=31,36 \mathrm{~N} / \mathrm{mnt}^{2}$ \\
\hline 5. Jenis semen & Ditetapkan & Tiga Roda tipe I \\
\hline 6. JeniAgregat : Kerikil, Pasir & $\begin{array}{l}\text { Ditetapkan } \\
\text { Ditetapkan }\end{array}$ & $\begin{array}{l}\text { Kerikil Kandangan } \\
\text { Pasir Rantau }\end{array}$ \\
\hline 7. Faktor air - semen bebas & & 0,58 \\
\hline $\begin{array}{l}\text { 8. Faktor air semen } \\
\text { maksimum }\end{array}$ & & 0,55 \\
\hline 9. Slump & & $50-80 \mathrm{~mm}$ \\
\hline 10.Ukuran agregat maksimum & Ditetapkan & $40 \mathrm{~mm}$ \\
\hline 11.Kadar air bebas & & $180 \mathrm{~kg} / \mathrm{m}^{3}$ \\
\hline 12.Kadar semen (rencana) & $11: 8$ atau 7 & $310,2=310 \mathrm{~kg} / \mathrm{m}^{3}$ \\
\hline 13. Kadar semen maksimum & Ditetapkan & $310 \mathrm{~kg} / \mathrm{m}^{3}$ \\
\hline 14. Kadar semen minimum & & $375 \mathrm{~kg} / \mathrm{m}^{3}$ \\
\hline 15.Faktor air - semen & Disesuaikan & 0,48 \\
\hline $\begin{array}{l}\text { 16. Susunan besar butir agregat } \\
\text { halus }\end{array}$ & & Zona I \\
\hline 17.Persen agregat halus & & $33 \%$ \\
\hline 18.BJ. Agregat relatif & $\begin{array}{l}(0,33 \times 1,846)+ \\
(0,67 \times 2,585)=\end{array}$ & 2,34 \\
\hline 19.BJ. beton & & $2207 \mathrm{~kg} / \mathrm{m}^{3}$ \\
\hline 20. Kadar agregat gabungan & $19-(20+15)$ & $1652 \mathrm{~kg} / \mathrm{m}^{3}$ \\
\hline 21.Kadar agregat halus & $17 \times 20$ & $545 \mathrm{~kg} / \mathrm{m}^{3}$ \\
\hline 22. Kadar agregat kasar & $20-21$ & $1107 \mathrm{~kg} / \mathrm{m}^{3}$ \\
\hline
\end{tabular}


(e)ISSN 2615-1847 $\quad$ (p)ISSN 2615-1839

Jurnal Manajemen Aset Infrastruktur \& Fasilitas - Vol. 3, Sup. 1, Juni 2019

Tabel 5b. Rangkuman Perencanaan Campuran

\begin{tabular}{lcccc}
\hline \multicolumn{1}{c}{ Proporsi Campuran } & $\begin{array}{c}\text { Semen } \\
(\mathbf{k g})\end{array}$ & $\begin{array}{c}\text { Air } \\
\mathbf{( k g )}\end{array}$ & $\begin{array}{c}\text { Agregat } \\
\text { Halus (kg) }\end{array}$ & $\begin{array}{c}\text { Agregat } \\
\text { Kasar (kg) }\end{array}$ \\
\hline Tiap $\mathrm{m}^{3}$ & 375 & 180 & 545 & 1107 \\
Tiap campuran Uji per $0,1 \mathrm{~m}^{3}$ & 37,5 & 18,0 & 54,5 & 110,7 \\
\hline
\end{tabular}


Tabel 6. Hasil Pemeriksaan Kuat Tekan Beton Variasi Ke-1 Dengan Kerikil: Kandangan; Pasir: Rantau; Air: PDAM dan Semen: Tiga Roda Semua Bahan Terlindung Dari Sinar Matahari, Temperatur Adukan $30^{\circ} \mathrm{C}$

\begin{tabular}{|c|c|c|c|c|c|c|c|c|c|c|c|c|c|c|}
\hline \multirow[b]{2}{*}{ No. } & \multirow[b]{2}{*}{$\begin{array}{l}\text { Umur } \\
\text { (hari) }\end{array}$} & \multirow[b]{2}{*}{$\begin{array}{c}\text { Berat } \\
\text { (gr) }\end{array}$} & \multirow[b]{2}{*}{$\begin{array}{c}\text { Benda } \\
\text { Uji }\end{array}$} & \multirow[b]{2}{*}{ Konversi } & \multirow[b]{2}{*}{ Slump } & \multirow[b]{2}{*}{$\begin{array}{c}\text { Ukuran } \\
\left(\mathrm{cm}^{2}\right)\end{array}$} & \multirow[b]{2}{*}{$\begin{array}{c}\text { Beban Max. } \\
(\mathrm{kg})\end{array}$} & \multicolumn{2}{|c|}{ Tekanan $\left(\mathrm{kg} / \mathrm{cm}^{2}\right)$} & \multirow[b]{2}{*}{$\begin{array}{c}\text { Rata-rata } \\
\left(\sigma_{\mathrm{mm}}\right)\end{array}$} & \multirow[b]{2}{*}{$\left(\sigma_{b}^{\prime}-\sigma_{b m}^{\prime}\right)$} & \multirow[b]{2}{*}{$\left(\sigma_{b}^{\prime}-\sigma_{b m}\right)^{2}$} & \multirow{2}{*}{$\begin{array}{c}\text { Standar } \\
\text { Deviasi } \\
(S)\end{array}$} & \multirow[b]{2}{*}{$\sigma_{\mathrm{bk}}{ }^{\prime}$} \\
\hline & & & & & & & & Hari & $\begin{array}{c}28 \text { hari } \\
\left(\sigma_{b}^{\prime}\right)\end{array}$ & & & & & \\
\hline 1. & 28 & 8106 & Kubus & 1.0 & 8 & 225 & 78380 & 348,36 & 348,36 & 337,30 & 11,06 & 112,32 & 16,52 & 310.19 \\
\hline 2. & 28 & 8152 & Kubus & 1.0 & 8 & 225 & 81180 & 360,80 & 360,80 & 337,30 & 28,50 & 552.25 & 16,52 & 310.19 \\
\hline 3. & 28 & 8016 & Kubus & 1.0 & 8 & 225 & 73580 & 327.02 & 327,02 & 337,30 & -10.68 & 105.68 & 16,52 & 310.19 \\
\hline 4. & 28 & 8327 & Kubus & 1.0 & 8 & 225 & 74030 & 329.02 & 329,02 & 337,30 & -8.28 & 68.56 & 16.52 & 310.19 \\
\hline 5. & 28 & 8293 & Kubus & 1.0 & 8 & 225 & 69100 & 307.11 & 307,11 & 337.30 & -30.19 & 911,44 & 16,52 & 310.19 \\
\hline 6. & 28 & 8174 & Kubus & 1.0 & 8 & 225 & 75450 & 335,33 & 335,33 & 337,30 & -1.97 & 3.88 & 16,52 & 310.19 \\
\hline 7. & 28 & 8344 & Kubus & 1,0 & 8 & 225 & 75700 & 336.44 & 336,44 & 337,30 & $-0,86$ & 0,74 & 16,52 & 310.19 \\
\hline 5. & 28 & 8180 & Kubus & 1,0 & 8 & 225 & 75480 & 335,47 & 335,47 & 337,30 & $-1,83$ & 3.35 & 16,52 & 310.19 \\
\hline 9. & 28 & 8234 & Kubus & 1.0 & 8 & 225 & 75950 & 337,56 & 337.56 & 337,30 & 0.26 & 0,07 & 16,52 & 310.19 \\
\hline 10. & 28 & 7981 & Kubus & 1,0 & 8 & 225 & 79450 & 353.11 & 353,11 & 337,30 & 15.81 & 249,96 & 16,52 & 310.19 \\
\hline 11. & 28 & 8041 & Kubus & 1.0 & 8 & 225 & 73700 & 327,56 & 327,56 & 337.30 & $-9,74$ & 94,87 & 16,52 & 310,19 \\
\hline 12. & 28 & 8215 & Kubus & 1.0 & 8 & 225 & 82030 & 364.58 & 364.58 & 337.30 & 27,28 & 744,20 & 16,52 & 310.19 \\
\hline 13. & 28 & 8255 & Kubus & 1.0 & 8 & 225 & 72850 & 323,78 & 323,78 & 337,30 & $-13,52$ & 182,79 & 16,52 & 310,19 \\
\hline 14. & 28 & 8063 & Kubus & 1,0 & 8 & 225 & 74940 & 333,07 & 333.07 & 337,30 & -4.23 & 17.89 & 16,52 & 310,10 \\
\hline 15. & 28 & 8062 & Kubus & 1.0 & 8 & 225 & 70900 & 315,11 & 315,11 & 337,30 & $-22,19$ & 492,40 & 16.52 & 310,19 \\
\hline 16. & 28 & 8174 & Kubus & 1,0 & 8 & 225 & 71050 & 315.78 & 315,78 & 337,30 & $-21,52$ & 463.11 & 16,52 & 310.19 \\
\hline 17. & 28 & 8130 & Kubus & 1.0 & 8 & 225 & 73950 & 328.67 & 328,67 & 337,30 & $-8,68$ & 74,48 & 16,52 & 310.19 \\
\hline 18. & 28 & 8321 & Kubus & 1.0 & 8 & 225 & 79430 & 353.02 & 353,02 & 337,30 & 15,72 & 247.12 & 16,52 & 310.19 \\
\hline 19. & 28 & 8185 & Kubus & 1.0 & 8 & 225 & 78950 & 350,59 & 350.59 & 337,30 & 13.59 & 184.69 & 16,52 & 310.19 \\
\hline 20. & 28 & 8117 & Kubus & 1,0 & 8 & 225 & 81730 & 363,24 & 363.24 & 337,30 & 25,94 & 672.88 & 16,52 & 310.19 \\
\hline \multicolumn{9}{|c|}{ Jumlah total } & 6745,92 & & & 5192,92 & & \\
\hline
\end{tabular}


Tabel 7. Hasil Pemeriksaan Kuat Tekan Beton Variasi Ke-2 Dengan Kerikil: Kandangan; Pasir: Rantau; Air: PDAM dan Semen: Tiga Roda Semua Bahan Tidak Terlindung Dari Sinar Matahari, Temperatur Adukan $40{ }^{\circ} \mathrm{C}$

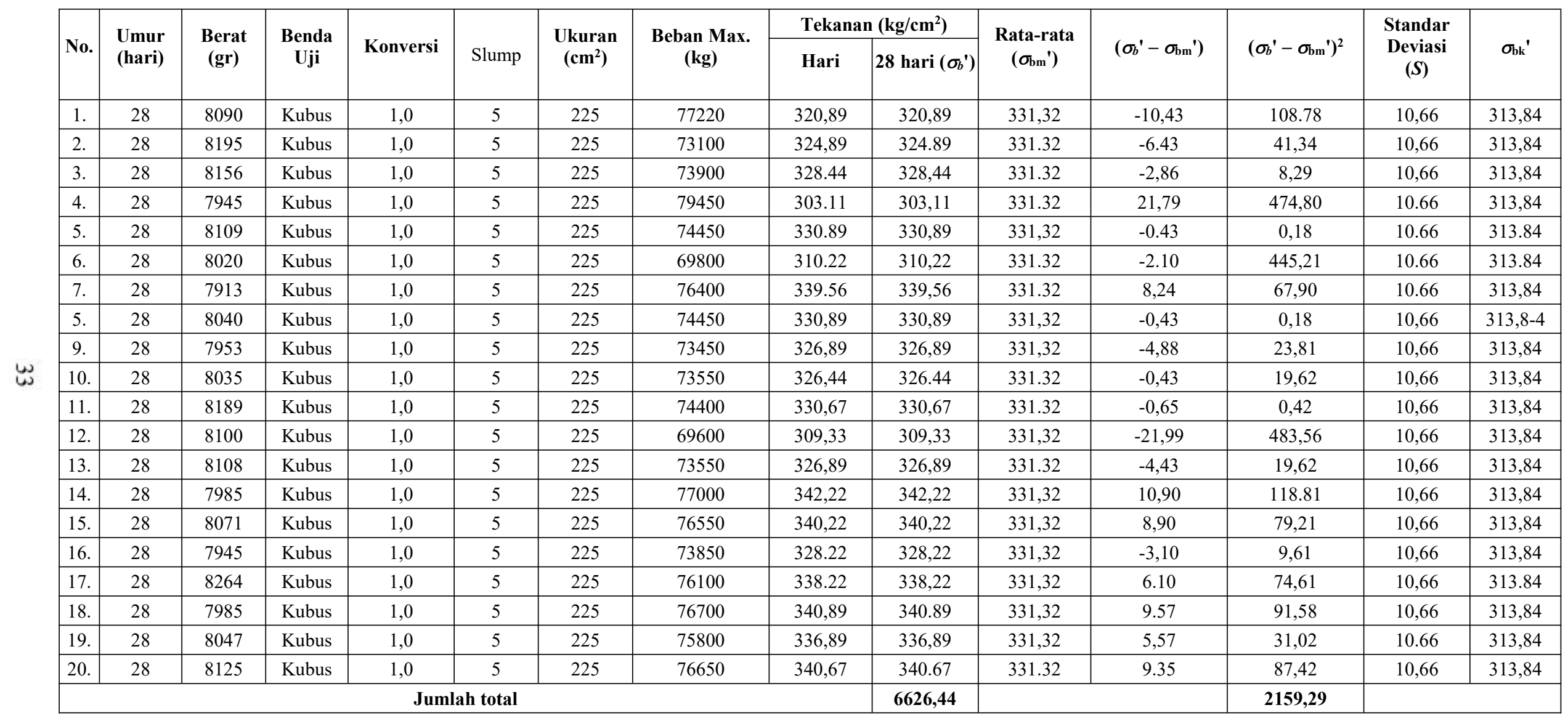


Tabel 8. Rangkuman Hasil Kuat Tekan Rata-rata dan Kuat Tekan Karakteristik Kedua Variasi Sampel

\begin{tabular}{ccc}
\hline Variasi & $\begin{array}{c}\text { Kuat Tekan } \\
\text { Rata-rata } \sigma_{\mathrm{bm}} \\
(\mathrm{kg} / \mathrm{cm} 2)\end{array}$ & $\begin{array}{c}\text { Kuat Tekan } \\
\text { Karekteristik } \sigma_{\mathrm{bk}} \\
(\mathrm{kg} / \mathrm{cm} 2)\end{array}$ \\
\hline I & 337,30 & 310,19 \\
\hline II & 331,32 & 313,84 \\
\hline
\end{tabular}

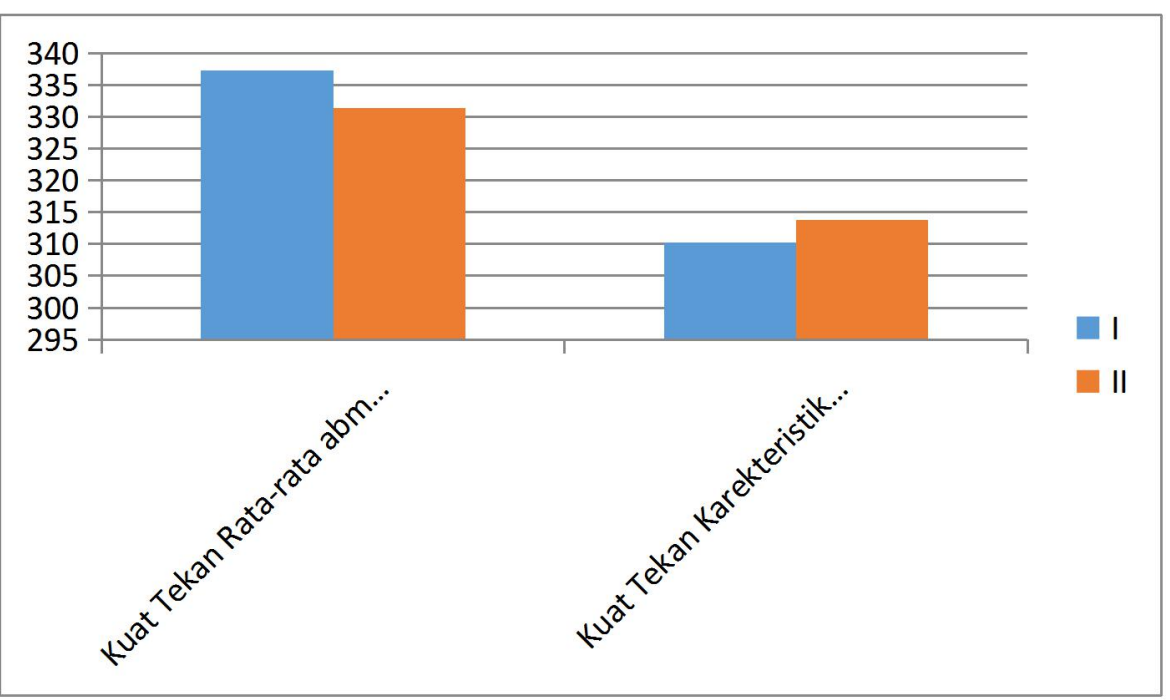

Gambar 1. Diagram Evaluasi Hasil Pemeriksaan Kekuatan Tekan Kedua Variasi Sampel

\section{KESIMPULAN}

Penelitian tentang pengaruh suhu campuran beton terhadap sifat dan mutu beton telah berhasil diselesaikan. Beberapa kesimpulan pokok disampaikan sebagai berikut :

- Agregat yang bertemperatur tinggi akibat panas matahari akan mempengaruhi faktor air-semen dalam adukan pasta semen.

- Faktor air-semen yang terganggu akibat temperatur tinggi pada agregat yang mengalami panas matahari mempengaruhi nilai slump.

- Kekurangan air pada pasta semen mengakibatkan proses hidrasi semen tidak selesai berlangsung sehingga pengikatan semen terhadap agregat tidak terjadi secara optimal.

\section{DAFTAR PUSTAKA}

Amiruddin (2011). Pengecoran Beton Saat Cuaca Panas Akibat Sinar Matahari. Diakses 13 Agustus 2018, dari https://lenterakecil.com/penulisan-daftar-pustaka-dari-internet/

FT ULM (1995). Petunjuk Praktikum Beton. Laboratorium Struktur dan Bahan. Fakultas Teknik. Universitas Lambung Mangkurat. Banjarmasin.

SNI 03-2834-2000. Standar Nasional Indonesia 03-2834-2000 tentangTata Cara Pembuatan Rencana Campuran Beton Normal.

Suprayitno, H. \& Soemitro, R.A.A. (2018). "Preliminary Reflexion on Basic Principle of Infrastructure Asset Management”. Jurnal Manajemen Aset Infrastruktur \& Fasilitas, Vol. 2, No. 1, Maret 2018, Hal : 1-10.

Tanjung, Jafril (1995). Sifat-sifat Dasar Beton Mutu Tinggi. Laboratorium Bahan Konstruksi. Jurusan Teknik Sipil. Universitas Andalas. Padang. 
(e)ISSN 2615-1847 $\quad$ (p)ISSN 2615-1839

Jurnal Manajemen Aset Infrastruktur \& Fasilitas - Vol. 3, Sup. 1, Juni 2019 